Supplement of J. Micropalaeontol., 37, 431-443, 2018

https://doi.org/10.5194/jm-37-431-2018-supplement

(C) Author(s) 2018. This work is distributed under

the Creative Commons Attribution 4.0 License.

(c) (1)

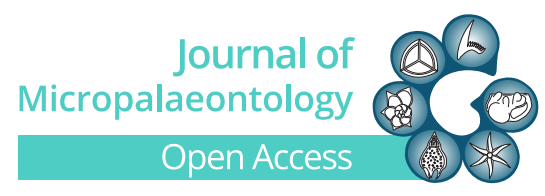

Supplement of

\title{
Factors affecting consistency and accuracy in identifying modern macrop- erforate planktonic foraminifera
}

Isabel S. Fenton et al.

Correspondence to: Isabel S. Fenton (isabel.fenton@ cantab.net)

The copyright of individual parts of the supplement might differ from the CC BY 4.0 License. 


\section{Section 1: Species list}

List of macroperforate species recognised in the study. The letters $(t, m, n)$ indicate whether the species was 'taught', 'mentioned' or 'not taught' on the NERC course. Participants were asked to indicate their confidence in identifying these.

1. Beella digitata (Brady, 1879) (n)

2. Globigerina bulloides d'Orbigny, $1826(\mathrm{~m})$

3. Globigerina falconensis Blow, 1959 (n)

4. Globigerinella adamsi (Banner \& Blow, 1959) (m)

5. Globigerinella calida (Parker, 1962) (t)

6. Globigerinella radians (Egger, 1893) (t)

7. Globigerinella siphonifera (d'Orbigny, 1839) (t)

8. Globigerinoides conglobatus (Brady, 1879) (t)

9. Globigerinoides elongatus (d'Orbigny, 1826) (t)

10. Globigerinoides ruber (pink) (d'Orbigny, 1839) (t)

11. Globigerinoides ruber (white) (d'Orbigny, 1839) (t)

12. Globoconella inflata (d'Orbigny, 1839) (n)

13. Globoquadrina conglomerata (Schwager, 1866) (m)

14. Globorotalia cavernula Bé, 1967 (n)

15. Globorotalia crassaformis (Galloway \& Wissler, 1927) (n)

16. Globorotalia hirsuta (d'Orbigny, 1839) (t)

17. Globorotalia menardii (Parker, Jones \& Brady, 1865 after d'Orbigny, 1826 nomen nudum) (t)

18. Globorotalia scitula (Brady, 1882) (t)

19. Globorotalia theyeri Fleisher, 1974 (n)

20. Globorotalia truncatulinoides (d'Orbigny, 1839) (n)

21. Globorotalia tumida (Brady, 1877) (t)

22. Globorotalia ungulata Bermúdez, 1961 (t)

23. Globorotaloides hexagonus (Natland, 1938) (n)

24. Globoturborotalita rubescens (Hofker, 1956) (t)

25. Globoturborotalita tenella (Parker, 1958)(m)

26. Neogloboquadrina dutertrei (d'Orbigny, 1839) (t)

27. Neogloboquadrina incompta (Cifelli, 1961) (t)

28. Neogloboquadrina pachyderma (Ehrenberg, 1862) (t)

29. Orbulina universa d'Orbigny, 1839 (t)

30. Pulleniatina obliquiloculata (Parker \& Jones, 1865) (t)

31. Sphaeroidinella dehiscens (Parker \& Jones, 1865) (n)

32. Trilobatus sacculifer (Brady, 1877) (t)

33. Trilobatus trilobus (Brady, 1877) (t), which includes T. immaturus (Leroy, 1939) and T. quadrilobatus (d'Orbigny 1846)

34. Turborotalita clarkei (Rögl \& Bolli, 1973) (n)

35. Turborotalita humilis (Brady, 1884) (n)

36. Turborotalita quinqueloba (Natland, 1938) (n) 


\section{Section 2: Repeatability questionnaire}

Name:

Email (for contact about the study over the coming months):

Academic career stage:

\section{Planktonic foraminiferal expertise}

How long have you been working with planktonic foraminifera?

Have you had any previous training on planktonic foraminiferal taxonomy (if so, what)?

Does your work require species level identification of planktonic foraminifera?

\section{Project area}

What is your main study group?

What is the main time period you focus on?

What is the main latitude you work with?

\section{Repeatability study}

Circle the point on the scale that best captures how the difficulty of identification matched your expectation.

$\begin{array}{lllllllllll}0 & 1 & 2 & 3 & 4 & 5 & 6 & 7 & 8 & 9 & 10\end{array}$

(Much easier)

(As I expected)

(Much harder)

What factors do you think might influence repeatability? 


\section{Section 3: Figures}

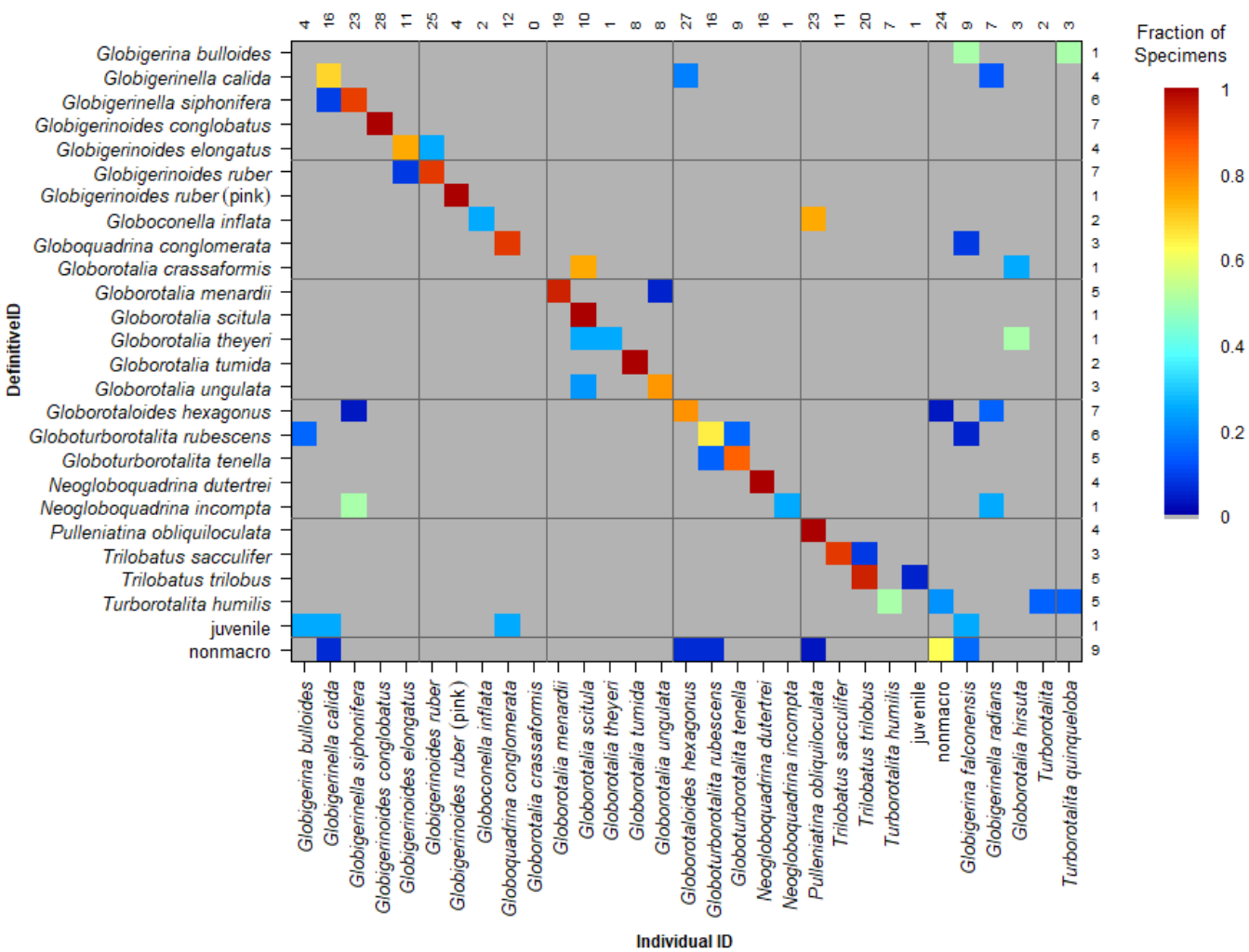

Figure S1 - Confusion matrix for experienced participants. The definitive ID is the taxonomic name considered correct in this study. The individual ID is the name which was given by the participant. For each definitive ID the coloured squares in that row indicate names which were used by the participants for that species. Grey cells indicate that that combination did not occur. If all specimens of all species were accurately identified then all the points would plot along the diagonal, with a fraction of 1 ; additionally each row sums to a fraction of 1 . The numbers on the right hand side refer to the number of specimens of that species in the study in the definitive ID. The numbers along the top refer to the number of times that species was identified in the study (n.b. specimens that were lost are excluded from this analysis). $\kappa=0.78$. A numerical version of this matrix is to be found in the data link. 


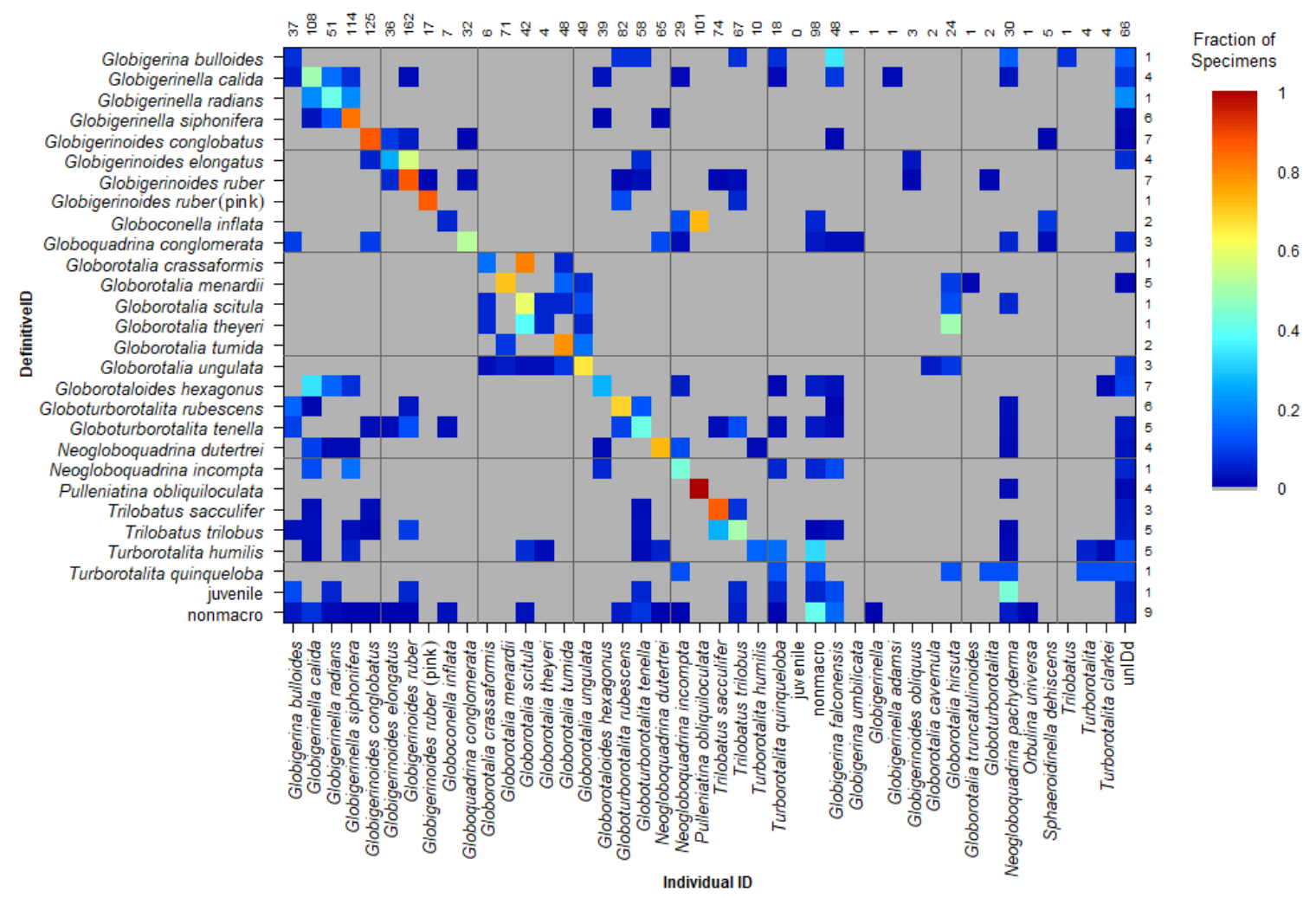

Figure S2 - Confusion matrix for less experienced participants. The definitive ID is the taxonomic name considered correct in this study. The individual ID is the name which was given by the participant. For each definitive ID the coloured squares in that row indicate names which were used by the participants for that species. Grey cells indicate that that combination did not occur. If all specimens of all species were accurately identified then all the points would plot along the diagonal, with a fraction of 1 ; additionally each row sums to a fraction of 1 . The numbers on the right hand side refer to the number of specimens of that species in the study in the definitive ID. The numbers along the top refer to the number of times that species was identified in the study (n.b. specimens that were lost are excluded from this analysis). $\kappa=0.54$. A numerical version of this matrix is to be found in the data link. 


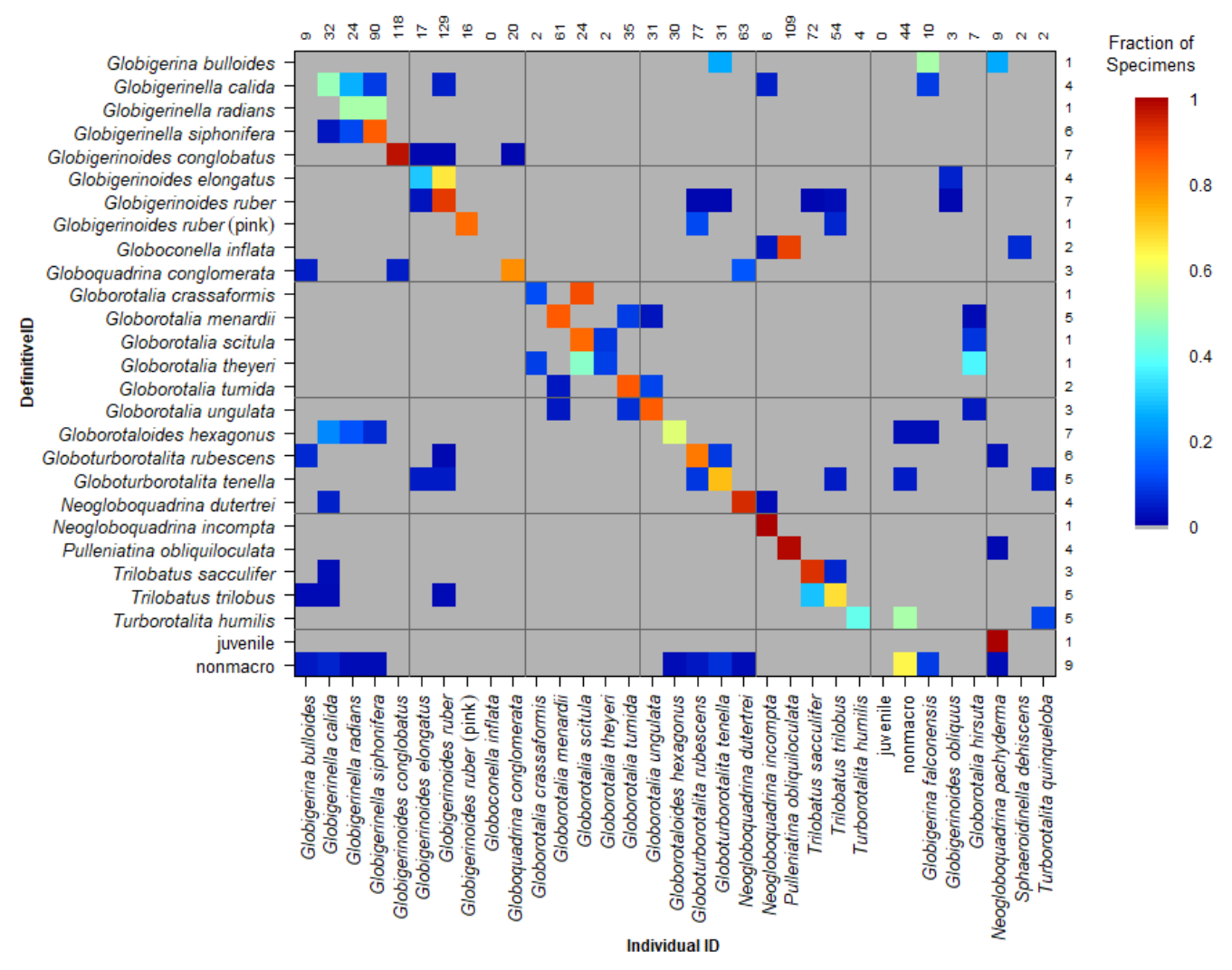

Figure S3 - Confusion matrix for confident identifications. The definitive ID is the taxonomic name considered correct in this study. The individual ID is the name which was given by the participant. For each definitive ID the coloured squares in that row indicate names which were used by the participants for that species. Grey cells indicate that that combination did not occur. If all specimens of all species were accurately identified then all the points would plot along the diagonal, with a fraction of 1; additionally each row sums to a fraction of 1 . The numbers on the right hand side refer to the number of specimens of that species in the study in the definitive ID. The numbers along the top refer to the number of times that species was identified in the study (n.b. specimens that were lost are excluded from this analysis). $\kappa=0.76$. A numerical version of this matrix is to be found in the data link. 


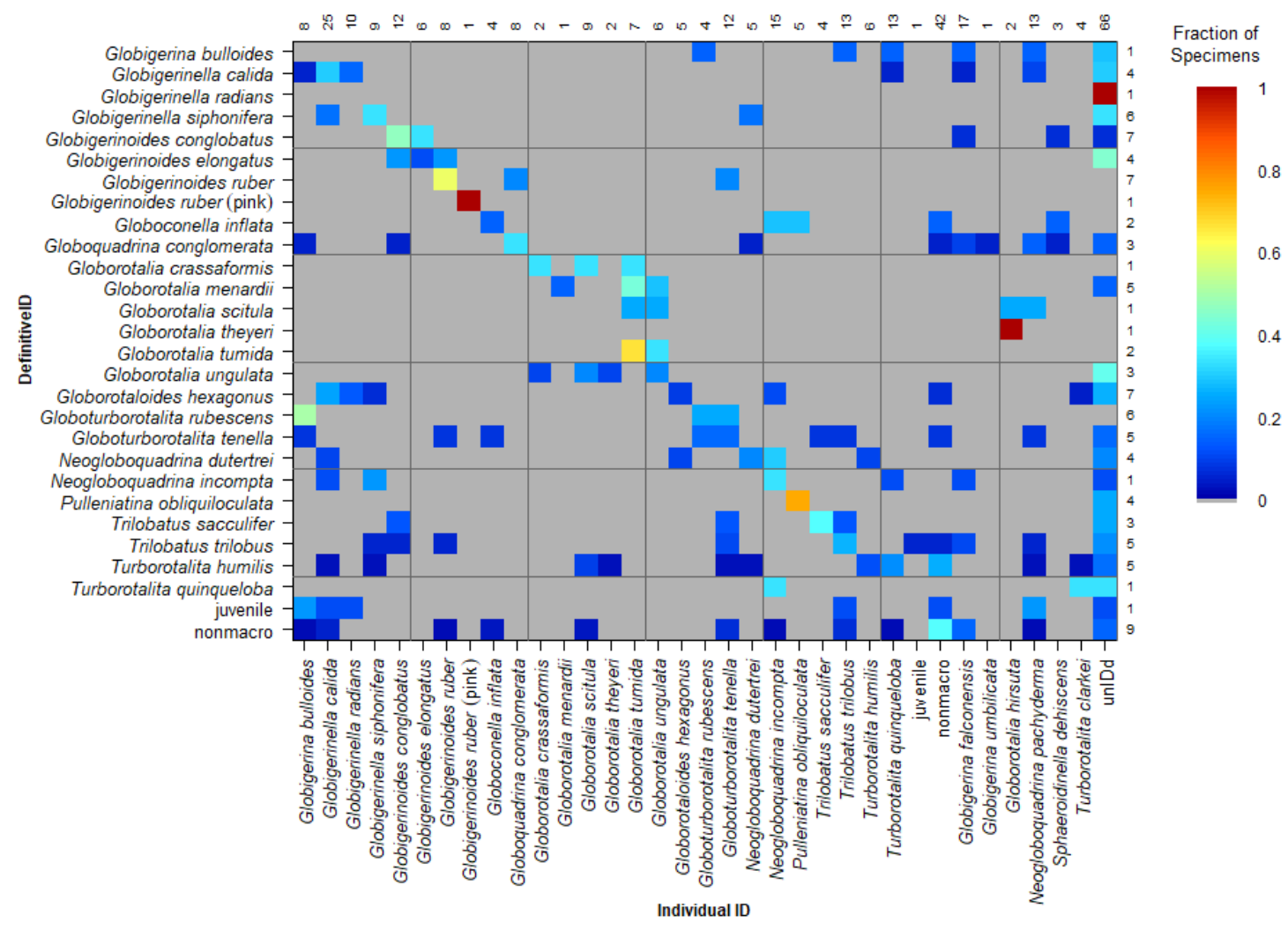

Figure S4 - Confusion matrix for unconfident identifications. The definitive ID is the taxonomic name considered correct in this study. The individual ID is the name which was given by the participant. For each definitive ID the coloured squares in that row indicate names which were used by the participants for that species. Grey cells indicate that that combination did not occur. If all specimens of all species were accurately identified then all the points would plot along the diagonal, with a fraction of 1; additionally each row sums to a fraction of 1 . The numbers on the right hand side refer to the number of specimens of that species in the study in the definitive ID. The numbers along the top refer to the number of times that species was identified in the study (n.b. specimens that were lost are excluded from this analysis). $\kappa=0.21$. A numerical version of this matrix is to be found in the data link. 


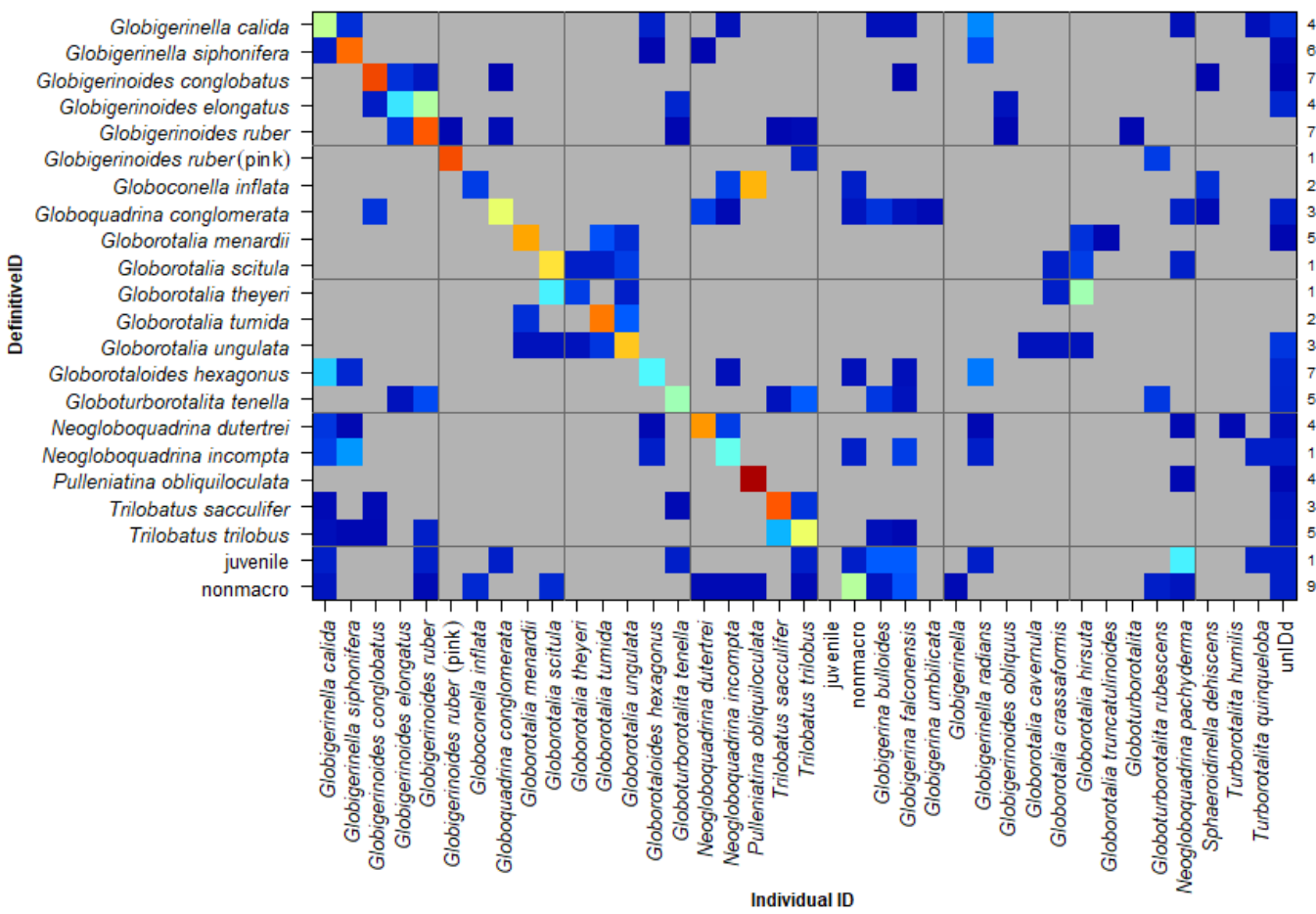

Figure S5 - Confusion matrix for specimens larger than $200 \mu \mathrm{m} . \kappa=0.64$.

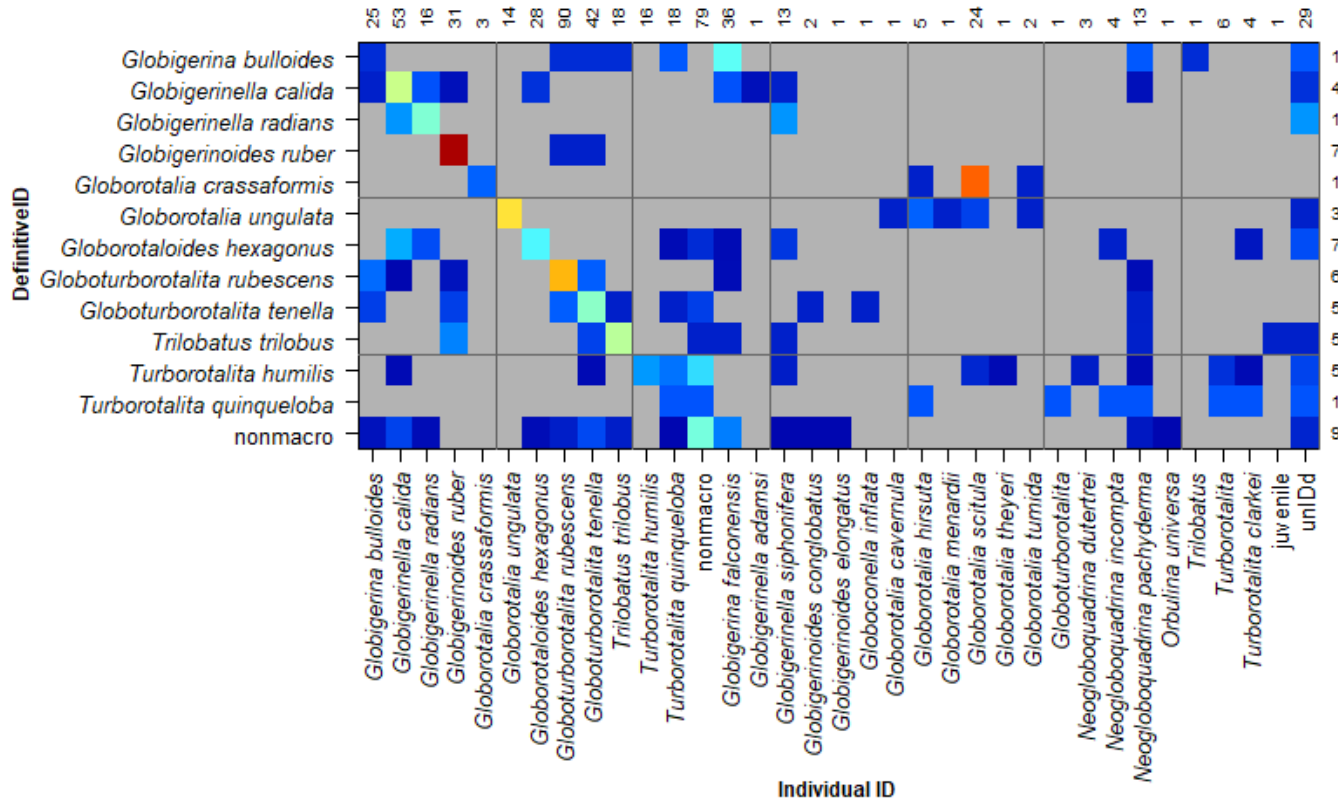

Fraction of

Specimens

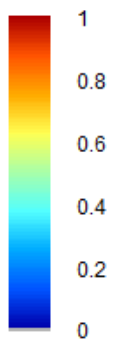

Figure S6 - Confusion matrix for specimens smaller than $200 \mu \mathrm{m} . \kappa=0.38$. 


\section{Section 4: Tables}

Table S1 - Comparing random error structures. All the combinations of the random effects were compared using the full model to determine the most appropriate random error structure. Random intercepts are indicated by $1 \mid \ldots$, whilst the random slopes are csLogMeanDia|...; / indicates the random effects are nested. This was chosen based on AIC. The full model is:

5 Corr $\sim \operatorname{csLogMeanDia*}($ HowLong + Taught $+\operatorname{csED}+$ Conf + SpConf + Experience + Gender $)$

\begin{tabular}{|c|c|c|c|c|c|c|c|c|}
\hline Random effects & $d f$ & AIC & BIC & logLik & deviance & $x^{2}$ & $\mathrm{x}^{2} d f$ & $p$-value \\
\hline (1|Person) & 29 & 1806.7 & 1967 & -874.33 & 1748.7 & - & - & - \\
\hline (1|DefinitiveID) & 29 & 1730.7 & 1891.1 & -836.4 & 1672.7 & 75.91 & 0 & $<2.2 \mathrm{e}-16$ \\
\hline (1|SpecNumber) & 29 & 1704.8 & 1865.2 & -823.4 & 1646.8 & 25.90 & 0 & $<2.2 \mathrm{e}-16$ \\
\hline$(1 \mid$ DefinitiveID $)+(1 \mid$ Person $)$ & 30 & 1726.3 & 1892.2 & -833.18 & 1666.3 & 0 & 1 & 1 \\
\hline (1|DefinitiveID/SpecNumber) & 30 & 1697.3 & 1863.2 & -818.6 & 1637.3 & 9.56 & 1 & 0.00199 \\
\hline$(1 \mid$ SpecNumber $)+(1 \mid$ Person $)$ & 30 & 1699.9 & 1865.8 & -820.0 & 1639.9 & 26.45 & 0 & $<2.2 \mathrm{e}-16$ \\
\hline$(1+$ csLogMeanDia|DefinitiveID) & 31 & 1731.7 & 1903.1 & -834.9 & 1669.7 & 0.00 & 0 & 1 \\
\hline$(1+$ csLogMeanDia|SpecNumber $)$ & 31 & 1696.4 & 1867.8 & -817.2 & 1634.4 & 35.30 & 0 & $<2.2 \mathrm{e}-16$ \\
\hline (1|DefinitiveID/SpecNumber) + (1|Person) & 31 & 1692.2 & 1863.6 & -815.1 & 1630.2 & 9.74 & 1 & 0.00181 \\
\hline$(1+$ csLogMeanDia|DefinitiveID $)+(1 \mid$ Person $)$ & 32 & 1727.2 & 1904.1 & -831.6 & 1663.2 & 0.00 & 1 & 1 \\
\hline$(1+$ csLogMeanDia|SpecNumber $)+(1 \mid$ Person $)$ & 32 & 1691.8 & 1868.7 & -813.9 & 1627.8 & 35.44 & 0 & $<2.2 \mathrm{e}-16$ \\
\hline$(1+$ csLogMeanDia|DefinitiveID/SpecNumber) & 34 & 1688.7 & 1876.7 & -810.4 & 1620.7 & 7.05 & 2 & 0.0294 \\
\hline$(1+$ csLogMeanDia|DefinitiveID/SpecNumber $)+(1 \mid$ Person $)$ & 35 & 1683.6 & 1877.2 & -806.8 & 1613.6 & 7.07 & 1 & 0.00783 \\
\hline
\end{tabular}

